go out into the community to describe and explain the unit's work has given the authorities and the families confidence in the unit and a realisation that it is concerned with them as people and not just with the results of the screening tests and the treatments prescribed. We believe that this, to a considerable extent, has been achieved by the creation of a liaison nursing sister post and with the invaluable wholehearted help of those regional health visitors who have been so keenly interested in the programme.

We are indebted to the health visitors in the North-western Region for their help and enthusiasm, to Mrs M A Riley for the psychological assessments, and to Miss Pat Chapman and the unit staff, who spent much time in acquiring the information on which the costing analysis was based.

\section{References}

1 Sardharwalla, I B, et al, Annals of Clinical Biochemistry, 1972, 9, 126.

2 Komrower, G M, Pediatrics, 1974, 53, 182.

3 Scriver, C R, Davies, E, and Cullen, A M, Lancet, 1964, 2, 230.

${ }^{4}$ Dryburgh, E H, Sardharwalla, I B, and Komrower, G M, Archives of Disease in Childhood, 1976, 51, 236.

${ }^{5}$ Fowler, B, et al, fournal of Clinical Investigation, 1978, 61, 645.

${ }^{6}$ Komrower, G M, et al, British Medical fournal, 1979, 1, 1383.

(Accepted 26 fuly 1979)

\title{
Patients' reactions to their investigations: a study of 504 patients
}

\author{
CLIFFORD HAWKINS
}

British Medical fournal, 1979, 2, 638-640

\section{Summary and conclusions}

Five hundred and four patients who had undergone hospital investigations were interviewed to find out how much information they had been given about the tests; their reactions before, during and after the test; and any after effects. In $74 \%$ of cases the tests had been satisfactorily explained. Patients were told more about complicated procedures such as cardiac catherisation than about routine ones such as venepuncture or barium meal examinations. The comments doctors made while performing the investigations were generally reassuring and were only rarely worrying or impatient. About half the patients suffered pain or discomfort during the test and rather more complained of after effects. Only $5 \%$ of patients said they would refuse the test again, though $36 \%$ said they would agree only reluctantly.

Communication lies at the heart of the problem. Hospitals should consider issuing handouts on investigations to back up the doctor's information and to dispel myths. Staff should be more careful in concealing frightening-looking equipment, and if patients have to wait during investigations it may help reduce their anxiety if they are provided with something to occupy their time.

\section{Introduction}

In many specialties advances in diagnosis have preceded those in treatment. Investigations are often uncomfortable, sometimes painful, and occasionally dangerous, ${ }^{1}$ apart from their great and increasing cost to the NHS. Yet little is known about their effect on patients. Although much has been written about communication with patients, ${ }^{2-5}$ the lack of information on patients' reactions to investigations is surprising, especially as failure to inform patients may have medicolegal consequences.

Queen Elizabeth Hospital, Birmingham B15 2TH CLIFFORD HAWKINS, MD, FRCP, consultant physician
This study was planned to find out what patients knew about their investigations, how much anxiety they had before and during them, and to what extent they suffered physical discomfort.

\section{Patients and methods}

Inpatients who had undergone investigation were interviewed using a coded questionnaire with 65 questions. Their mental clarity was also recorded.

Interviews were carried out over three years by three interviewers; none had special training in the technique of interviewing, though each had spent her professional career in this field, one being head of a personnel department and the other two working in psychiatry. Each dressed informally and made it clear to the patient that her object was to obtain a detached and independent opinion and that she was not part of the establishment. Interviews took place in the hospital, generally in the ward, but where there was no possibility of others overhearing.

The questionnaire was divided into three parts, covering before the test, during it, and afterwards. Patients were asked: before the interview -whether the test was explained and by whom, whether the patient understood and knew where it was going to be done, and whether he was frightened or terrified (using a mood adjective check list); during the test-how much of the procedure was remembered, whether any discomfort, pain, or other effects were noticed, and whether any comments were heard-either reassuring, worrying or irrelevant; after the test-whether the patient would have the test repeated (no, yes, or reluctantly); whether the test affected the patient in any way (better, no change or worse), and whether any suggestions could be offered for making the test easier for other patients.

The answers were put on to IBM cards and analysed by a punch card sorter.

\section{Results}

Five hundred and four patients from 13 medical and eight surgical wards were interviewed; 462 were chosen by random selection and 42 otherwise included. They were almost equally divided between the sexes: 264 men and 240 women. Their age range is given in table I. Four hundred and seventy-six were mentally clear, and 28 were slightly confused or had a speech difficulty though not sufficient to prevent them being satisfactory witnesses. Four hundred and fifty-seven were United Kingdom subjects, seven were from Eire, four from Europe, and 36 were immigrants; a language problem occurred in 14 but measures were taken to ensure that questions were understood. The 
interview lasted less than half an hour for 129 patients, half to one hour for 362, and over one hour for 13. The time that interview took place after the investigation is shown in table II. Reactions of patients to 26 different investigations (table III), both invasive and noninvasive, were assessed.

TABLE I-Age distribution of the 504 patients studied

\begin{tabular}{|c|c|c|c|c|c|c|c|c|c|c|}
\hline & & Age (years): & $11-20$ & -30 & -40 & -50 & -60 & -70 & -80 & -90 \\
\hline $\begin{array}{l}\text { Men } \\
\text { Women }\end{array}$ & 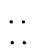 & $\because$. & $\begin{array}{r}16 \\
7\end{array}$ & $\begin{array}{l}26 \\
18\end{array}$ & $\begin{array}{l}20 \\
22\end{array}$ & $\begin{array}{l}39 \\
39\end{array}$ & $\begin{array}{l}65 \\
59\end{array}$ & $\begin{array}{l}49 \\
82\end{array}$ & $\begin{array}{l}21 \\
28\end{array}$ & $\begin{array}{l}4 \\
9\end{array}$ \\
\hline Total & & & 23 & 44 & 42 & 78 & 124 & 131 & 49 & 13 \\
\hline
\end{tabular}

TABLE II-Time after investigation that interview took place

\begin{tabular}{|c|c|c|c|c|c|c|c|}
\hline $\begin{array}{l}\text { Time (days): Same day } 1 \\
\text { Patients }\end{array}$ & $\begin{array}{r}2 \\
99\end{array}$ & $\begin{array}{r}3 \\
39\end{array}$ & $\begin{array}{r}4 \\
23\end{array}$ & $\begin{array}{r}5 \\
29\end{array}$ & $\begin{array}{c}6-10 \\
62\end{array}$ & $\begin{array}{c}11-2 C \\
24\end{array}$ & $\begin{array}{cc}21-30 & -30 \\
10 & 9\end{array}$ \\
\hline
\end{tabular}

TABLE III-Number of patients undergoing various investigations

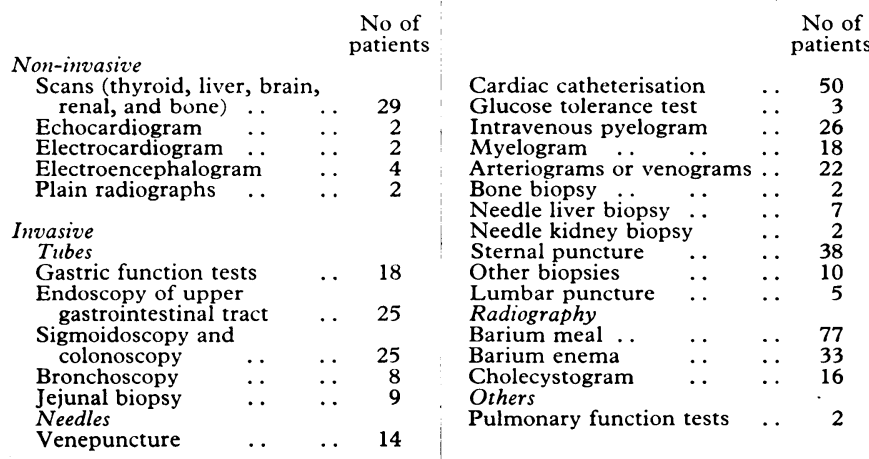

BEFORE THE TEST

One hundred and five patients had had the test before or knew about it and so were excluded from the analysis of the question about how well the test had been explained. In the remaining 399 the tests had been explained satisfactorily to 295 patients $\left(74_{i 0}^{\circ}\right)$ and only partly explained in $42(10 \%) ; 62(16 \%)$ said that the test had not been explained. The extent to which the test was explained varied with the type of investigation (table IV). Biopsies of bones, liver, or kidney were explained in nearly all cases and endoscopy and cardiac catheterisation in the vast majority of cases, but common investigations such as barium meals and venepuncture were explained in far fewer cases. Doctors, either consultants or junior staff, were generally responsible for providing information and nursing staff only occasionally. One ward of 30 patients with two consultants and a sister specially interested in ensuring that the medical staff talked properly to patients were compared with all other wards; $78 \%$ of their patients said that their test had been explained, in contrast to $54 \%$ in the rest. Three hundred and ninety-four patients had been told where the investigation was being done but 110 did not know.

Two hundred and seventy-one patients were not frightened, 176 were anxious or apprehensive, and 57 were frightened. There was no statistical difference between men and women.

TABLE IV-Answers to question "Was the test explained to you?"

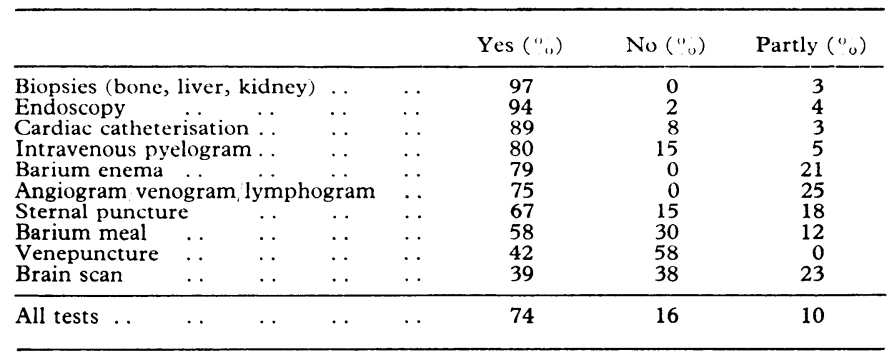

DURING THE TEST

Four hundred and eighty-seven patients remembered to varying extents the test being done. Seventeen could not remember because of premedication. Three hundred and thirty-six $(67 \%)$ said that they were not frightened during the test, whereas $140(28 \%)$ were apprehensive and $28\left(6^{\circ} \%\right)$ were frightened or terrified. One hundred and seventy-nine $(75 \%)$ men were not frightened, $54(23 \%)$ were apprehensive, and seven (3\%) were frightened compared with $155(59 \%)$ women who were not frightened, $86(33 \%)$ who were apprehensive, and $21(8 \%)$ who were frightened or terrified. When asked whether any discomfort or pain was felt during the test, 256 said they had none, 206 complained of discomfort, 23 had slight pain, four had moderate pain, and 15 suffered severe pain. The difference between men and women was not statistically significant.

Doctors talk during tests and patients were asked whether they noticed any asides. Two hundred and fifty-seven heard nothing; the rest heard conversation, which was reassuring in 202 cases, irrelevant in 32 , worrying in 11 , and simply impatient remarks from the doctor in two.

\section{AFTER THE TEST}

After the test 272 patients suffered from after effects whereas 232 had none. Men and women were equally distributed in complaining of these $(55 \%$ and $53 \%$ respectively). Generally the types of after effect from individual tests were those expected-for example, sore throat after endoscopy and constipation after barium. Certain after effects were unexpected such as headache, tiredness, and other vague symptoms, which may have been due to the stress of the tests:

A key question was whether the patient would have the test repeated. Twenty-five said they would refuse to have the test again; 296 would agree, and 183 would agree though reluctantly. Again, there was no significant difference between men and women. The figure shows the answers of patients to individual tests.

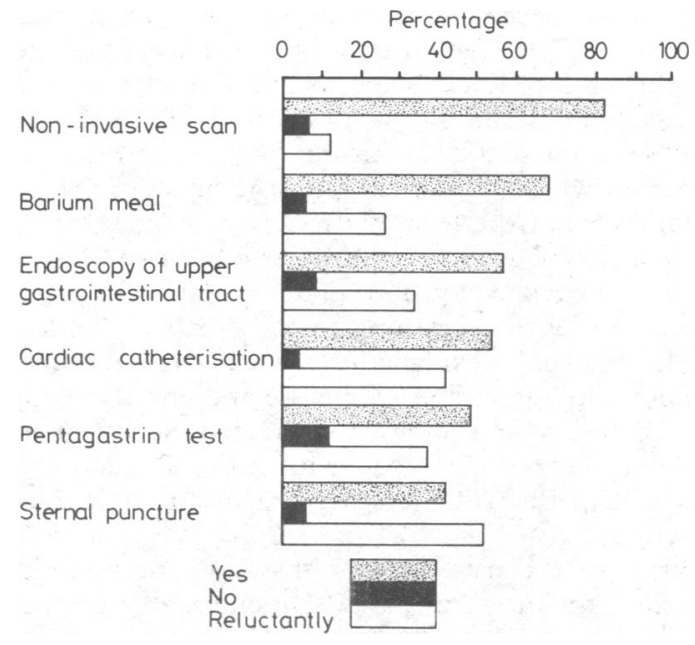

Answers to question whether patients would undergo the test again for five individual tests.

To the question "Has the test affected you in any way ?" 42 patients said that they felt better-because they were relieved the test was over, because they felt that "something was being done," or because they experienced actual physical improvement such as disappearance of diarrhoea after a barium enema. Four hundred and thirty-two noted no change and 30 felt worse.

\section{COMPLAINTS}

Communication lay at the heart of the problem. Many patients thought that they ought to have been better informed. Delays, waiting, and postponements were sometimes not explained. Some would have preferred to know how long the test lasted, to have a running com- 
mentary, and to be told when it was completed. Several complained that they were not told the results. Where the investigation was carried out came in for comment. Some had to wait in a corridor and found it cold and uncomfortable. Equipment and machinery as in the $x$-ray or cardiological department struck fear into some; even the sight of someone approaching with a syringe caused alarm. One young woman was worried about the effect of $x$ rays on her reproductive organs. Instructions were difficult to hear because of background noise like the clatter of $x$-ray plates being inserted. For certain tests, such as a barium progress meal, waiting was necessary, and then boredom was added to anxiety, especially if the patient had nothing to do. Some patients had disabilities which increased their problemsfor example, patients with arthritis had difficulty in turning over on a couch and the $x$-ray table appeared even harder. Fear of needles was very common and was still present in one doctor who had had venepunctures over many years. Some were terrified at the thought of swallowing a tube. One woman who suffered from claustrophobia found it very unpleasant when the $x$-ray machine zoomed down over her. Slight deafness, not apparent to the operator, made it even more difficult to hear instructions in a busy and somewhat noisy department.

The physical side effects of tests were generally as expected. For example, two out of 50 patients felt discomfort or pain when the cardiac catheter was going up the arm, 12 described a hot flush, presumably when the radio-opaque dye was injected, two had a sudden desire to urinate, and one of these also to defecate; others complained of palpitations and one of cold feet. Afterwards 18 had a sore arm and 15 felt tired or drowsy. Of 16 patients who underwent myelography, seven complained of discomfort during the test and three disliked being strapped down on the $x$-ray table; and afterwards eight had a sore back, four pain in a leg, and two a headache. Some patients found that preparation for a test-for example, cleansing the bowel before colonoscopy-was worse than the test itself.

\section{Discussion}

Any attempt to get hard data on patients' reactions to investigations is fraught with difficulty. The interview itself has many variables, and it is easy for questions to be misconstrued. The desire to please the doctor or to be stoical may cause biased answers. Also patients easily forget what has been said, though this is less likely with diagnosis and tests than with explanations about the illness. ${ }^{6}{ }^{7}$ Home is a better place than hospital to interview the patient but has the disadvantage that a longer period will have elapsed after the finish of the test.

Measurement of the level of anxiety or degree of fright can only be approximate as emotions are subjective. Also patients are not a homogeneous group: some are always fearful, some are content to leave everything to the doctor, whereas others, more critical, want an explanation at each stage. About one-half were anxious and apprehensive before and one-third apprehensive during the test and some were terrified. Some patients were frightened of everything to do with hospitals, and it may be difficult to help them. Others may be in an anxiety state and need a sedative.

A quarter of the patients said that the test was either not explained or explained only partly. Patients were informed about complex and unusual tests whereas less information was given about routine ones like venepuncture or barium meal, probably because the medical and nursing staff assumed that they already knew about them. Wards vary greatly in the level of communication, and this depends especially on the attitude of the consultant and sister in charge. Details about tests are obtained from doctors and nurses, and some patients prefer the nurses as their language is easier to understand. Patients are often misinformed by other patients who give distorted accounts of their own tests or quote from bygone days-for example, for a barium meal patients no longer have to swallow a pint of barium in the dark, just a cupful in a dimmed room. Handouts can be useful to complement bedside talks and counteract lurid tales of other patients. The fact that procedures such as blood tests and chest radiographs are "routine" reassures many, and this word could be mentioned in the booklet issued by hospitals for patients.

Delays and postponements occur in every hospital and are often unavoidable, but waiting increases the stress. Worry is reduced if the patient is kept in the picture and something is provided to occupy the time: every department should consider the need for magazines, books, radio, or even television, especially when waiting is inevitable, such as during barium progress meals. Moving about on a hard $x$-ray table, particularly for the frail and crippled, is a common complaint. Unfortunately, it seems that the $x$-ray table cannot be made less hard without increasing the geometrical distortion on $x$-ray films. Equipment frightens many, and nurses and medical students should be taught the importance of concealing this; for example, the sight of a duodenoscope or sigmoidoscope is enough to cause tension and reduce the compliance of the patient. Compliance is important: time is wasted if patients are not properly informed and arrive with a full stomach for barium meal or other gastric investigation. Human contact is helpful during a worrying test, such as a nurse holding the patient's hand, and the patter of the doctor can act as a tranquilliser; on the other hand, the doctors' asides can be misinterpreted or offend the patient-for example, a teetotaler undergoing gastroscopy may be offended if he overhears "may be alcoholic gastritis." The fact that only two patients heard impatient remarks was a credit to those carrying out tests such as cardiac catheterisation, which may be difficult and frustrating. It was also a credit to the patients that so many would agree to have the investigation again; naturally, a noninvasive scan was generally accepted whereas many were reluctant to undergo cardiac catheterisation, swallow tubes, or have a sternal puncture.

Nevertheless, the amount of anxiety beforehand is not related to the seriousness of the test, and the idea of a barium meal may cause more worry than that of cardiac catheterisation. Certain departments provide more problems for the patients, and the study by Wild and Evans ${ }^{8}$ clearly defined those that might arise in the $x$-ray department; these workers suggested that some member of the departmental staff might be responsible in a general sense for the patients' welfare.

All tests out of the blue can be terrifying, even an approach with syringe and needle without explanation. Most patients, especially those in hospital for the first time, need to be informed about even the simplest test because they have no knowledge of what it entails, and it is the expectation of the unknown which is so upsetting. Also many are not in their normal state of mind and are much more easily upset than usual. Patients are less anxious if they know what to expect and what is expected of them. ${ }^{9}$ Patients "admitted for investigations" are approaching the unknown whereas those on the waiting list for operations know what to expect and usually expect success.

This research was financed by a grant from the West Midlands Regional Health Authority. Interviews were carried out by Miss Dorothy Wright, Mrs Marjorie Halstead, and Mrs Barbara Quinton. I should also like to thank my colleagues who allowed their patients to be interviewed and Mr L Dallow and Mrs J Harold in the hospital statistics department for their technical help in analysing the results.

\section{References}

1 Vogel, J H K, Chest, 1975, 67, 131.

2 Cartwright, A, Human Relations and Hospital Care. London, Routledge and Kegan Paul, 1964.

${ }^{3}$ Hawkins, C F, Speaking and Writing in Medicine. Springfield, Thomas, 1967.

${ }^{4}$ Fletcher, C M, Communications in Medicine. London, Nuffield Provincial Hospitals Trust, 1973.

5 Bennett, A E, (editor), Communications Between Doctors and Patients. London, Nuffield Provincial Hospitals Trust, 1976.

${ }^{6}$ Ley, P, and Spelman, M S, Communicating with the Patient. London, Staples, 1967.

' Joyce, C R B, et al, Quarterly fournal of Medicine, 1969, 38, 183.

${ }^{8}$ Wild, A A, and Evans, J, British Medical fournal, 1968, 2, 607.

${ }^{9}$ Wilson-Barnett, J, British Medical fournal, 1978, 1, 1324.

(Accepted 23 fuly 1979) 